\title{
SANATÇI ADAYI ÜSTÜN YETENEKLII ÇOCUKLARI OLAN AİLELERİN KARŞILAŞTIĞI SORUNLAR ÜZERİNE BİR ARAŞTIRMA
}

\author{
A Research Towards The Problems That Encountered By \\ Families Who Have Performer Candidate Gifted Children
}

DOI NO: 10.5578/amrj.67082

\author{
Fakı Can YÜRÜK ${ }^{1}$
}

\begin{abstract}
Özet
Ülkemizde mesleki müzik eğitimi veren kurumlar çeşitli yaş gruplarında ögrenci kabul eder. Konservatuvar eğitimi ortaokuldan itibaren hatta yarl zamanl olarak ilkokul yaşlarından itibaren ögrenci kabul etmesi ile farklı bir konumdadır. Özellikle çalgı eğitiminin çok küçük yaşlarda başlaması geleneği kurumsallaşmış konservatuvarlarda ve dünyanın her yerinde kabul edilmiş bir görüş̧ür. Hemen her öğrencinin yetenekli olarak kabul gördügü bu okullarda üstün yetenekli ve farkl öğrenen çocuk ve gençlere de slk sik rastlanır. Bununla birlikte; okul, veli ve ögrrenci profesyonel müzik eğitimi süreci içerisinde birçok sorunla karşılaş̧maktadır. Bu sorunların çözümüne yönelik ise tutarl bir politikanın hayata geçirilememiş olması özellikle ailelerin bazı sorunlar yaşamalarına neden olabilmektedir. Ayrıca Cumhuriyetin kuruluşundan itibaren başlayan, 1948'li yıllarda kurumsallaşan üstün yetenekli sanatçı adaylarına verilen destekler son 30 yılda kesintiye uğramıştır.

Bu araştırmada 'Sanatçı adayı üstün yetenekli çocukları olan ailelerin karşılaş̧tı̆̆ sorunlara yönelik düşünceleri nedir?' sorusuna cevap aranmış, örnek bir aile üzerinde durulmuştur. Mevcut sorunlar ailenin tecrübeleri doğrultusunda betimlenmeye çalışlmış örnek olay olarak nitelendirilebilecek çallşmada yapılandirılmuş görüşme ile elde edilen veriler, içerik analizi tekniği ile işlenerek bulgulara ulaşılmıştır. Çalışmanın konu özelinde özgün olduğu, bu tür çocuklart olan ailelerin sosyal desteğe duydukları ihtiyaçların tespitinde önemli veriler sunacağl ve alana katkl sağlayacağı düşünülmektedir. Ayrıca sorunların çözümlenmesinde de ailenin yaşamış oldukları doğrultusunda üstün yetenekli ailelere de yol göstereceği düşünülmektedir.
\end{abstract}

Anahtar Kelimeler: Yetenek, Üstün Yetenek, Sanatçı.

\footnotetext{
${ }^{1}$ Öğr. Grv., Afyon Kocatepe Üniversitesi, Devlet Konservatuvarı, fakicanyuruk@aku.edu.tr
} 


\begin{abstract}
The institutes which give professional music education in our country accept students from different age groups. Conservatory education is in a different position in that it accepts students from middle school or even half-time schooling from elementary school. The tradition of starting the instrument education in early ages is an approved remark in institutionalized conservatories and all over the world. In those schools, in which most students are accepted as talented, gifted students who learn different can also commonly beseen. Furthermore; school, parent and student encounter lots of problems during the professional music education process. It is thought that no consistent policy can be accomplished towards those problems' solutions and especially the families are left helpless.The support given to the gifted performer candidates, which started from the establishment of the Republic and became institutionalized in 1948, has been interrupted in the last 30 years.

In the study in which 'What are the thoughts of the families, who have gifted children, towards the problems they encountered?' question is searched for answer, it will be dwelled on a sample family and the problems will be represented towards family's experiences. In the phenomenology grounded study data collected by interviewing was analysed with reference to qualitative analysis techniques. It is thought that the study is unique specific to the subject, to determining the expectations of family from government, it will contribute to the field and it will give new and different thoughts for analysing the problems.
\end{abstract}

Keywords: Talent, Superior Ability, Performer.

\title{
Konservatuvarlar ve Üstün Yetenekliler
}

Ülkemizde mesleki müzik eğitimi veren kurumların sayısı son yıllarda hızla artmıştır. Örneğin 2018 yılı itibariyle konservatuvar sayıs1 47'dir. Tam zamanlı olarak ortaokul birinci sinıftan yarı zamanlı olarak ise ilkokul birinci sınıftan itibaren öğrenci kabul eden konservatuvarların ülkemiz mesleki müzik eğitimi veren kurumlar arasında ayrı bir yeri ve önemi vardır. Eğitim, icra, besteleme ve araştırma boyutlarında müziği meslek olarak seçen bireylerin yerleştiği ve istihdam olanağ 1 verdiği bu okulların; sosyal, kültürel, ekonomik, toplumsal birçok işlevi vardır. Toplumun kültürel değişim ve gelişimine katkılarının olduğu görüşü ise yaygın olarak kabul görür.

$\mathrm{Bu}$ okulların eğitim öğretim sürecindeki, bir diğer deyişle eğitim sistemindeki en önemli ögeleri hiç kuşkusuz; öğrenci, veli, okul ve öğretmendir. 
Konservatuvar öğrencisi ciddi ve titiz bir yetenek testinden geçer ve öğrenci olarak kabul edilir. Öğrenciler arasında üstün yeteneklilere de sık sık rastlanır.

Sistem işte bu noktada bazı sıkıntılar yaşamaya başlar. Farklı olan ve öğrenen bireylerin eğitim gördüğü bu okullarda üstün yetenekli öğrencilerle karşılaşıldığında her zaman ve her yerde aynı verim alınamamaktadır.

Burada karşılaşılan sorunlar arasında en büyük etkenin veli, öğretmen, öğrenci, okul, sosyal çevre ve sosyal devletin yapması gerekenler veya üzerine düşen görevlerin neler olduğu konusunda yeterli çalışma yapılmamış olması bulunmaktadır.

80 milyonluk bir ülkede elbette farklı öğrenen, deha ve üstün yetenekli birçok birey olacaktır. Bu bireylerin heba olup gitmeden yetiştirilmeleri ve ülkenin yetiştirdiği değerler arasında yerlerini almaları gerekmektedir. Yetenekli çocukların kaybolup gitmesi ve kültürel alanda verecekleri hizmetin alınamaması büyük bir sorun olarak görülmelidir.

Başarılı bir süreç için birçok faktörün aynı felsefe içerisinde davranması, bir bütün olması gerekmektedir.

Müzik pedagogu Lavignac'ın yetenek üzerine düşünceleri dikkat çekicidir. Lavignac'a göre çocuğun musiki muhiti önemlidir. "Çocuğun müstakbel inkişafında tesiri bulunması dolayısı ile mühim olarak bizi meşgul edecek bir şey varsa, o da çocuğun ilk seneler zarfındaki muhiti, teneffüs ettiği hava ve etrafında daimi suretle bulunanların musiki dereceleridir" (1939: 12)

Lavignac üstün yeteneklileri, dâhileri prodij olarak adlandırmıştır. Ona göre üstün yeteneklilerin kaybolma riski de vardır. $\mathrm{Bu}$ nedenle keşfedildikleri andan itibaren üzerlerine titizlikle eğilmek ve çalıştırılmaları konusunda özenli bir sürece tabi tutulmaları önemlidir.

Büyük üstatlardan birçoğunun çocukluklarında prodij (dahi) olduklarını belirtir. Fakat bu üstatların sayısının, müzik ile uğraşan, her sene takdir edilmiş ve sonra ümitleri boşa çıkarmış çocuklar kütlesine nazaran, pek az olduğunu vurgular. Müzik yeteneğinin çocuklarda çok erken yaşlarda başladığını söyler. Fakat ergenlik dönemine ulaştıklarında (erkek çocuklarda on beş ile yirmi yaş, kız çocuklarda on dört ile on yedi yaş arası) bu yeteneğin bir buhran geçirdiğini, hafiflediğini ve bir daha uyanmamak üzere uyuduğunu 
anlatır. Ancak bu çıkılması güç devreyi geçirebilenlerin büyük sanatçı olabildiklerini, bunların da pek az olduğunu dile getirir. (Lavignac, 1939: 20).

Ayrıca, "Hakiki profesörün karakteristik alameti kendisini talebesine sevdirmesini bilmesidir. Çünkü bu suretle derslerine ait bütün şeyleri de onlara aynı zamanda sevdirmiş olur. Ders saati bir sevinç saati olmalıdır. Çocuğun, profesörü sevinçli bir sabırsızlıkla beklediği görülecek olursa bu kendisine iyi bir öğretmen bulunduğuna delildir" sözleriyle öğretmenin önemine de değinir (Lavignac, 1939: 51).

Lavignac; ebeveynin de profesöre karşı vazifeleri olduğuna inanır. Ailenin derse katılması, çocuğun ders tekrarlarını yaptırması önemlidir. Bunda öğretmenin izin vermesine dikkat edilmelidir. Ebeveynler ders ve süreci hakkında özellikle çocuğun yanında fikir beyan etmemelidirler (1939: 55-56).

Lavignac'a göre keman çalınması en zor sazlardan biridir. Alt1 ile sekiz yaş arası en ideal başlama yaşı1dır (1939: 121).

Lavignac'ın düşünceleri sistem içerisindeki tüm paydaşları ilgilendirmektedir.

Say'da benzer örnekler verir Ona göre yeteneğin birçok anlamı ve tanımı vardır. "Yetenek, tutkuya dönüşmüş sevginin, kural ve korku tanımayan ürünüdür" "Özgür olma" ya yönelmektir (2001: 55). Say'a göre "sahip çıkılmayan, yetenek olgusu ise ciddi bir sorundur. Yetenekli kişi için de, toplum için de" (2001: 56).

Williams öğretme'nin bir bilim değil sanat olduğunu öğrenmemiz gerektiğini söyler. Ona göre bu işi yapan öğretmenin rolü ise potansiyelimizi ortaya çıkarmada bize yardım eden kişidir (1998: 43).

Fazıl Say'ın konu özelinde fikri önemlidir. "Hocalarımın üçüyle de usta çırak ilişkisi içinde çalıştım" (2001: 27). Der ve ekler "Olabilecek en iyi pedagogla, en tatlı insanla başladım piyanoya. Dört yaşındaki bir çocuğa müziği sevdirmek, müziği bir oyun gibi göstermek, fazla çalıştırarak müzikten soğutmamak, ama aynı zamanda hızlı ve tutarlı bir çizgi tutturmak, neresinden bakarsanız bakın büyük hünerdir" (2001: 26-27).

"Romen besteci-kemancı George Enescu'yu beş yaşında bir harika çocukken büyük bir keman öğretmenine götürdüler. Maestro, alçak gönüllülük göstererek "Pekala, küçük adam, dedi” sanırım bana 
neler yapabileceğini göstereceksin.” Öfkesi burnunda küçük oğlan "Önce siz gösterin, öyle" diye yanıtını yapıştırdı. Yumurcak Enescu, öğretmenin keman performansıyla müzik yargısına güvenebileceğine emin olmadan nuh dedi peygamber demedi" (Kaufmann, 2000: 249).

Yaşanmış bir hikâyeden çıkarılacak sonuç oldukça basittir. Öğrencinin öğretmenine inanması lazımdır. Ülkemiz konservatuvarlarındaki eğitimcilerin, sanatçı adayı bireylerin içlerindeki potansiyelleri ortaya çıkarmada yeterli olduğu düşünülmekle beraber üstün yetenekli bireylere karşı nasıl bir tutum ve davranış sergileyecekleri hususunda sürekli iletişim ve bilgi, tecrübe alışverişlerinde olunmasının yararı vardır.

Dünyaca ünlü keman sanatçısı Yehudi Menuhin "Çocuklarımın Müzik Yeteneği Olsaydı" adlı yazısında öğretmenin önemi üzerinde durur, okulun ise yeterli olmadığını şu sözlerle dile getirir. "Çocuğumun yeteneği ve müzikçi olmak isteği benim karşı çıkmalarımı yenerse, o zaman babamın bana yaptığını yapardım. Ona dünyanın en iyi öğretmenlerini tutar, kafasını karıştıracak uğraşlardan uzaklaştırır ve genel kültürünü özel bir öğretmen aracılığıyla tamamlardım" (Say, 2005: 34).

Farklı öğrenenlere karşı nasıl tutum ve davranışlar gerekir önemsenmelidir. "Öğrenme hızının normal öğrencilere oranla hızlı bir gelişim göstermesi durumu da son derece zor ve dikkate alınması gereken bir durumdur" (Türkmen, 2016: 134).

Ülkemizde üstün yetenekli çocukların ailelerine yönelik hizmet veren ve onlara yol gösteren kurumlar oldukça azdır. Sanatçı adayı çocuğu ile birlikte yaşamayı ve onların gelişimlerine katkıda bulunmayı el yordamı ile sürdürmektedirler. $\mathrm{Bu}$ alanda hizmet veren rehberleri de yoktur. Rol modellerinin tecrübe ve birikimleri ise sözlü anlatımdan öteye geçmemektedir. Aile; sosyal çevre ve ekonomik baskılarla da mücadele yöntemlerini kendi kendilerine geliştirmektedirler. Kurumsal destek için başvuracakları bir merkez de henüz bulunmamaktadır.

Say kendinden örnek verir. "Doğrusu yurt dışına gitmek istiyordum, ama kendimi tanıtmak için, sanatımı dinletmek, sanatımı kabul ettirmek için! $\mathrm{Bu}$ amaca ulaşmanın tek yolu olduğu söyleniyordu: Yurt dışı öğrenim için burs bulmak... Türk devleti "sanat eğitimi" için burs vermiyordu. Peki, nasıl olacaktı? İşin bu tarafını pek düşünmüyordum. Yumurta kapıya geldiği zaman bile kaygılanmadım. Konservatuvarı bitirmeme birkaç ay kala, yaşamımı 
yeni bir yörüngeye oturtacak beklenmedik bir olayla karşılaştım. Ünlü Alman besteci Aribert Reimann ve piyanist David Levine, yetenekli gençleri keşfetmek göreviyle Ankara'ya gelmişler. Güney Amerika'yı, Uzakdoğu ve bazı Ortadoğu ülkelerini tarayarak sürdürüyorlarmış keşfi. Meselenin bu yönünü tabii ki bilmiyordum" (2001: 35).

Say gibi kaç öğrenci yurt dışı hayali kurmakta? Kaçının bu hayali gerçekleşmekte? Yetenek arayanalar Anadolu'nun kaç iline gidebildiler? Bu imkânlardan kaç öğrencimiz faydalanabildi?

Say'ın örnek alınacak bir ailesi baba modeli var. Mithat Fenmen, Kamuran Gündemir ve David Levine gibi çok önemli üç eğitimci ile çalışma imkânı elde etmiş. Keşfedilmiş. Peki, tüm bu süreçleri ülkemizde kaç öğrenci başarı ile geçebiliyor?

Cumhuriyet'in kurulduğu ilk y1llarda sanata, kültüre ve müziğe değer verildi. Müzik öğrenimi için Avrupa'ya yetenekli gençler gönderildi (Yalman, 2017: 281). 1948 yılında ise "Harika Çocuk Yasası" kabul edildi. İdil Biret, Suna Kan'la başlayan Oya Ünler'le devam eden ve en son Emrecan Yavuz'la son bulduğu bilinen resmi gönderimler maalesef son 30 yılda kesintiye uğradı

Say haklı olarak sormakta: "Son y1llarda, hatta son on beş yılda, yurtdışı öğrenimi için devletin bir müzikçiye burs verdiğini ben duymadım. Ya siz?" (2001: 115).

\section{Çalışmada Amaç, Önem ve Yöntem}

Tüm açıklamalar 1şığında; bu çalışmada; sanatçı adayı üstün yetenekli çocukları olan ailelerin karşılaştığı sorunların tespitine yönelik düşüncelerinin ne olduğunun öğrenilmesi amaciyla yapılandırılmış görüşme tekniği uygulanmıştır. Görüşmeden elde edilen veriler içerik analizi yoluyla irdelenmiş ve bulgulardan sonuçlara gidilmiştir.

Araştırmanın konu itibarlıyla özgün olduğu, ailenin özellikle kurumsal destek açısından beklentilerinin belirlenmesinin önemli olduğu ve alana katkı sağlayacağı, sorunların çözümlenmesinde yeni ve farklı fikirler vereceği düşünülmektedir.

Araştırma bilinçli örnekleme yoluyla seçilen ve araştırmaya gönüllü olarak katılan sanatçı adayı keman öğrencisi Neva Bildik'in anne ve babası ile gerçekleştirilmiş, gönüllü olarak katıldıkları araştırmada görüşme sorularına titizlikle cevap vermişlerdir. 
Çalışmada;

Çocuğun özelleri nedir?

Çocuğun ve ailenin sanat eğitimi başlangıcında yaşadıkları nelerdir?

Çocuğun ve ailenin sanat eğitimi sürecinde yaşadıkları nelerdir?

Çocuğun eğitim sürecine etki eden etmenler nelerdir? aranmıştır.

Ailenin devletten beklentileri nelerdir? Sorularına yanıt

\section{BULGULAR VE YORUM}

Neva Bildik Özgeçmişi konusunda şunlar anlatılmıştır:

"31.07.2009 Tarihinde doğdu. Keman eğitimine 4,5 yaşında Afyon CAKA'da başladı ve iki yll burada eğitim aldı. 2016 Yılında Bilkent Keman Günleri açıllş programında sahne aldı. Burada Cihat Asskın'ın ustalık sinıfina katıldı. Daha sonra Mersin Üniversitesi Devlet Konservatuvarı özel yetenek sinavinı kazanarak Lily Tchumburidze'nin yarı zamanl ögrencisi olmaya hak kazand ve halen eğitimini sürdürmektedir. 27 Mart 2018 tarihinde İzmir Devlet Senfoni Orkestrası'nın açtığı solist seçim sinavinı kazanarak 20 Nisan 2018'de solist kemancı olarak sahne almıştır. Ayrıca 27 Nisan-1 Mayls 2018 tarihleri arasinda Slovakya'da düzenlenen 22nd International Competition of Bohdan Warchal in playing the bow string instruments yarışmasinda ülkemizi temsil ederek 1. Kategoride 2. lik ödülüne laylk görülmüştür"

Neva Bildik Ailesi ile Yapılan Görüşme

Çocuğunuz diğer sanat alanlarından (resim, tiyatro, drama vb) hangilerine ilgi duymaktadır?

"Halk oyunlart ve edebiyat"

Yeteneğini ilk ne zaman ve nasıl fark ettiniz?

"1 yaş civarında. Dinlediği şarkıları doğru bir biçimde söyleyebilmesi ve 3 yaşında kendince besteler yapmaya çalışması bize müzik alanında kabiliyeti olduğunu düşündürttü." 
Müzikte hangi alanlardaki (belleği, ritim kabiliyeti, ezgiyi yeniden tanıması, ilgisi, sesleri algılaması vb) yeteneği fark ettiniz?

"Bellek, ritim kabiliyeti, ezgiye uygun bir biçimde dans etmesi, müzik dinleme konusundaki ilgisi ve ezgiyi yeniden tanıması fark etmemize neden oldu."

İlk eğitimine nasıl ve ne zaman başladı

"Evde albümlerini dinlediğimiz bir arp sanatçısından etkilenerek arp çalmak istediğini ifade ediyordu. Daha sonra kreşteki müzik ögretmeninin keman çalmasindan etkilenerek keman çalmak istediğini belirtmiştir. Bir tesadüf sonucu Afyonkarahisar'da CAKA'nın faaliyet gösterdiğini ögrendik ve eğitmenlerle görüştük onların kabul etmesi üzerine ilk eğitimine 4.5 yaşta Afyon CAKA 'da başladi. Keman eğitimi ile birlikte Afyon Kocatepe Üniversitesi minikler korosunda iki yll korist olarak yer aldl. Bir yll boyunca ise AKSAM Türk Dünyası Çocuk korosuna devam etti"

Burada ailelerin çocuklarındaki yetenekleri fark edebilmelerine yönelik gerekli dikkatin gösterilmesi ve yeteneklerini gözlerinde büyütmeden ama küçümsemeden doğru bir tespitle yapabilmelerinin önemi ortaya çıkmaktadır. Araştırmanın konusu olan ailenin çocuğun eğilimlerine göre hareket etmesi yeteneğinin geliştirilmesi ve ortaya çıkarak belirginleşmesinde önemli bir rol oynamış gözükmektedir.

Hedefleriniz ve planlamalarınız nasıl değişti?

"Aile olarak çocuğumuzun yeteneğinin ne boyutta olduğu ve neler yapacă̆ konusunda bir kestirmede bulunmamız müzisyen olmadı̆̆ımı için söz konusu değildi. Dolayısıyla bu konuda keman ögretmenlerinin önerileri ve yönlendirmelerini son derece ciddiye aldik ve Türkiye'deki erken müzik eğitimi konusunda araştırmalar yapmaya başladık. 2016 yılındaki keman alanındaki dünyaca ünlü pedagogların katıldiğı 2. Bilkent Keman Günleri'ne katılmaya karar verdik. Orada Neva'nın profesyonel olarak keman eğitimine devam etmesi gerektiği yolundaki uzman görüsleri kesin karar vermemizi sağladl. Özellikle çocuğumuzun kemancılarla birlikte olmaktan duyduğu mutluluk ve israrla konservatuarda eğitim görmek istediğini belirtmesi aslında başka bir yol da bırakmadı bizim için. Bir sürü farklı süreç ve sıkıntılardan sonra Nevâ Mersin Üniversitesi'nde Lily Tchumburidze'nin 
ögrencisi olarak özel yetenek sinaviyla yarı zamanlı öğrenci olmaya hak kazandl."

Burada ailenin çocuğun yeteneklerini işlemek ve daha iyi bir eğitim aldırabilmek konusunda gösterdiği titizlik ve çocuğun eğilimlerini karşılamak çabası önemli bir etken olarak görülmektedir. Keman öğretmenlerinin yönlendirmelerini dikkate almaları ve bir sonraki aşamaya yönlendirilen çocuğun yeteneklerini işleyecek pedagoglara bulundukları şehirde ulaşamamaları ve bu nedenle yer değiştirmek zorunda kalmaları yaşadıkları zorlukların başında gelmektedir.

Süreçte (eğitim, konser, resital, yarışma vb) neler yaşandı?

"Yeni bir şehir, yeni bir ev yeni bir ilkokul anne-babanın tayin süreci çocuğun arkadaşlarından ayrılmasının yanı sıra konservatuar eğitiminin ilk yllında çalışma disiplini konusunda bazı zorluklar yaşadık. Küçük yaşta belli alışkanlıkların kazandırılmasinın önemine ek olarak bu alışkanlıkların kazandırılması için bazen 24 saatlik bir çaba, araştırma ve düşünme süreci gerekebiliyor. Özellikle de kemanin zor bir enstrüman olmasi săg el, sol el, tutuş gibi birbiriyle eşgüdüm halindeki süreçleri içermesi ve bizim bu konuda bilgisiz olmamı bizi endişelere sevk etti. Lily Tchumburidze'nin bu konudaki rehberliği sayesinde bu sorunu büyük oranda aştığımızı düşünüyorum”.

"Mersin Üniversitesi Devlet Konservatuari'nda periyodik olarak gerçekleşen konser ve dinletilerde öğrencilerin sahne tecrübesi kazanması sağlanıyor. 1,5 ylllı yarı zamanlı eğitim süreci içerisinde Nevâ'nın ilerlemesine bağll olarak konser programları belirlendi. Bu yıl tecrübe kazanması amacıyla İmir Devlet Senfoni Orkestrası'nın açtığ solist seçim sinavina katılan ve kazanan Nevâ 20 Nisan 2018'de solist olarak sahneye çıtıt. Daha sonra Uluslararası 22. Bohdan Warchal Yaylı çalgılar yarışmasında 2. oldu. Yarışmaya kendisinden yaşça büyük ve yarışma tecrübesi olan katılımcıların arasinda ilk yarışmasinda derece elde etmesi gerçekten beklediğimiz bir sonuç değildi.

Yarışmanın en güzel yanı Avrupa'nın farklı ülkelerinden insanlarla tanışmak ve onlardaki müzik eğitiminin nasıl olduğunu görmek oldu." 
Ailenin bu noktada araştırmalarının ve çabuk harekete geçmelerinin daha büyük sorunların yaşanmasına engel olduğu ve süreci daha kolay atlatmalarını sağladığı anlaşılmaktadır.

Desteklemenizin amacı neydi?

"Ĕ̈itimci birer anne-baba olarak çocukların ancak potansiyellerini ortaya koyduklarında mutlu, sağlıklı ve insanlı̆̆a faydalı olabileceğine inandiğımızdan çocuğumuzun kendini gerçekleştirme sürecini hangi alanda olursa olsun desteklemeyi düşünüyorduk."

Okul ve eğitimci seçme sürecinde neler yaşadınız?

"Masterclass için başvurduğumuz Bilkent Keman Günlerinde Bilkent Üniversitesi Keman Pedagogu Muhammed Jan Turdiev'in dikkatini çeken Nevâ 1 ay Afyonkarahisar'dan her hafta sonu Ankara'ya giderek ders aldi. Muhammed Jan Turdiev'in Bilkent'ten ayrlması üzerine 1 ay boyunca da Hacettepe Üniversitesi Devlet Konservatuarindan Reyyan Yücel Başaran'dan ders aldl. Daha sonra Bilkent Keman günlerinde kendisi ve ögrencileriyle tanıştı̆̆ımı Lily Tchumburidze ile iletişim kurarak Neva'yı ögrenci olarak alıp alamayacağımızı sorduk. Kendisi bizi Mersin'e davet etti. Nevâ özel yetenek sinavin geçerek yarı zamanlı ögrenci olarak kabul edildi." var $\mathrm{m} 1$ ?

Harika Çocuk Kanunu (7 Temmuz 1948) hakkında bilginiz

"Evet var."

Bu yasa tekrar aktif olsun ister misiniz?

"Evet isteriz"

Çocuğunuz için yurt dişı eğitimin önemi sizce nedir?

"Şu durumda olmazsa olmaz bir derecede önemli olduğunu düşünüyorum." misiniz?

Çocuğunuzla birlikte yurt dışı eğitimi için gitmek ister "Evet"

Çocuğunuzun aldığı eğitimi destekleyici ortamların (sanat, sosyal, bilimsel, teknik) olduğunu düşünüyor musunuz? 
"Konser, gezi, kitap fuarlarl, spor faaliyetlerini kendi imkânlarımızla planlayıp gerçekleştirmekteyiz."

Çocuğunuzun başarısında neler etkili oldu?

"Doğru insanlarla tanışmak, destekleyici sosyal çevre her gün düzenli çalışma ve en önemlisi tecrübeli bir pedagogla çalışma." misiniz?

Çocuğunuzun çalışma saatleri hakkında bilgi verebilir

"Çalışma saatleri ve süresi çallş̧lacak eser ve parçalara göre değişkenlik göstermekle birlikte ortalama 2 saattir. Hafta sonlar bu süre uzayabilmektedir."

Enstrüman ve diğer ekipmanları bulmada (tel vb) sorunlar yaşamakta misınız?

"Maalesef özellikle iyi enstrüman bulma konusu ülkemizde sıkıntı. Diğer ekipmanların Euro ile satılması maddi anlamda külfet getiriyor."

Burada yine bir soruna değindikleri görülmektedir. Özellikle doğru pedagoglarla çalışması gereği bir kez daha ortaya çıkmaktadır. $\mathrm{Bu}$ sorunu maddi sorunlar takip etmekte, enstrüman ve diğer ekipmanların sağlanması konusunda da sıkıntı yaşadıkları anlaşılmaktadır.

Çocuğunuzun akranlarına göre keman eğitimindeki gelişim aşamaları nasıl?

"Aşamaları daha hılı geçtiği keman öğretmeni tarafindan belirtilmektedir."

Çocuğunuzun gelişiminde keman öğretmeninin rolü nedir?

"Karakter gelişimi, sosyal gelişimi, hırstan uzak bir kişilik geliştirmesi, kendine güven ve merak duygusunun pekiştirilmesi açısından olumlu bir rolü vardır."

Destekleyici dersler (solfej, teori, tarih vb) alıyor musunuz?

"Haftada 1 gün solfej dersi ( Konservatuar eğitim programına dâhil) ve ihtiyaç duyulan zamanlarda piyano öğretmeninden özel eşlik dersi."

Yurt içi ve yurt dışı yarışmaları ve sınavları hakkında neler düşünüyorsunuz? 
"Doğru yarışma ve uygun kategori seçilirse öğrenciye çok katkı sağlayacağını düşünüyoruz".

Yurt dışı yarışma deneyiminiz nasıldı?

"Farklı insanlarla farkll kültürlerle karşılaşmak bu deneyimin en güzel anıydı. Nevâ'nın ilk katıldı̆̆ yarışmada derece alması ve özellikle de jüri üyelerinin ayrı ayrı beğenilerini ifade etmeleri teknik ve müzikalite ile ilgili övgülerde bulunmaları yarışmanin en mutlu edici yaniydı diyebilirim."

Yurt içinde ilgi ve destekler neler? vermeleri."

"Senfoni Orkestralarının sinavlar açıp çocuk solistlere şans

Şu anda içinde bulunduğunuz durumda süreci de dikkate alarak hangi sorunlardan bahsetmek istersiniz?

"Erken müzik eğitiminin anasınıfi yaşından itibaren Devlet Konservatuvarlarında başlamamasinı sorun olarak görüyorum. Yarl zamanl eğitiminde ders sayısı ve süresinin az olması, piyano eşlik dersi olmaması, yurtdışı yarışma ve masterclass ücretlerinin çok yüksek olması."

Üstün yetenekli çocuk ailesi olarak yaşadıkları sorunlar, erken yaşta müzik eğitiminin başlayamaması,

Yarı zamanlı eğitimde ders sayı ve süresinin az olması, eşlik dersinin olmamas1,

Yurt dışı masterclass ve yarışma ücretlerinin yüksek olması biçiminde sıralanmıştır.

Devletten ve devletin kurumlarından beklentileriniz neler?

"Üstün yetenekli çocuklar için fonlar ayrılması ve eğitimlerinin maddi ve manevi açıdan desteklenmesi."

Çocuğunuzun geleceği üzerine beklentileriniz, dilek ve temennileriniz neler?

"İşini çok seven, ülkesini en iyi bir biçimde gururla temsil eden, kaliteli müzik yapan, bilgi ve birikimini aktarabilen iyi bir kemancı olmasinı istiyoruz."

Ailelere neler söylemek istersiniz? Ailenin çocuğuna, öğretmenine karşı vazifeleri sizce neler? 
"Doğru bir müzik eğitimi için kendi yaşam biçimlerini de düzenlemeleri gerektiğini ve bunun zaman zaman çok yıpratıcı olabileceğini belli bir disiplin ve sürekliliğin olması gerektiğini ve çok sabırlı olunması gerektiğini söylemek isterim."

"Çocuğu değerlendirirken gerçekçi ve duygusallıktan uzak değerlendirmeler yapılmasının çok önemli olduğunun bilincinde olarak çocuğa yetenekten çok çabanın önemli olduğunun hissettirilmesi en büyük sorumluluklardan biridir diye düsünüyorum. Ayrıca teknolojik aletlerin kullanımının akılcl bir biçimde olması, değişik ilgi alanlarının desteklenmesi de çocuğa karşı sorumluluklar arasında sayllabilir."

"Ailenin ögretmenlere karşı vazifesi ise işbirliğine açı olmak, yapılan uyarlar dikkate almak verilen ödev ve görevlerin yerine getirilebilmesi için uygun ortamı oluşturmaktır diyebilirim"

Son sözlerinizi almak isteriz.

"Müzikle dinleyici olarak ilgilenen bir aile olarak sadece çocukla empati kurmanin, onunla içten bir şekilde ilgilenmenin, araştırmanın ve birlikte öğrenmenin çocuğun her alandaki başarısinda çok etkili olduğunu deneyimlediğimizi son söz olarak eklemek isteriz. Çalışmalarınızda başarılar diler teşekkür ederiz."

\section{Tartışma ve Sonuçlar}

Ülkemiz konservatuvarlarının çoğu lisans düzeyinde eğitim öğretime başlamaktadırlar. Bu da maalesef birçok yetenekli ve hatta üstün yetenekli farklı öğrenen çocukların değerlendirilmemesine yol açmaktadır.

Aile ile yapılan görüşme sonucunda;

Çocuğun müziği ve diğer sanat dallarını sevmesinin ciddi ve yorucu bir çalg1 eğitimine girmesinde büyük bir etki yaptığ1 anlaşılmaktadır. Yeteneğin çok küçük yaşlarda anlaşılabileceği aile tarafından dile getirilmiştir. Bulundukları ilde CAKA (Cihat Aşkın ve Küçük Arkadaşları) keman eğitimi projesinin olması ise büyük bir şans olarak görülmüş ve aile tarafından değerlendirilmiş̧ir. 
Çocuğun ve ailenin sanat eğitimi başlangıcında bazı imkânlara sahip olması yanında bulundukları ilde yarı zamanlı bir konservatuvarın olmaması ise büyük bir engel olarak karşılarına çıkmış ve il değiştirmek zorunda kalmışlardır. Ailenin ekonomik durumu ve iş hayatında zor da olsa yer değiștirme imkânı bulması önemlidir ama her aile aynı imkânlara sahip olamayabilir.

Çocuğun ve ailenin sanat eğitimi sürecinde doğru keman eğitimcileri ile buluşması, çocuğun bu eğitimcileri ve süreci sevmesi dikkat çekmektedir. Bununla birlikte yeni bir sosyal çevre, uyum çocuktan ziyade aileyi zorladığı anlaşılmıştır. Çocuğun hayatı ve yaşantısını henüz bir oyun olarak görmesi buna neden olarak gösterilebilir.

Çocuğun eğitim sürecine, gelişme çizgisine ve konser gibi sonuçlara bakıldığında nitelikli ve dünyaca tanınmış keman eğitimcilerinin başarısı hemen gözlenmektedir.

Yarı zamanlı eğitimde ders sayısı ve süresinin azlığı, piyano eşlik desteğinin olmaması, yurt dışı masterclas ve yarışma ücretlerinin yüksekliği aile tarafından en önemli sorunlar olarak dile getirilmektedir.

Harika çocuk yasasının aktifleşmesi, yurt dışı desteğin verilmesi, çocukla beraber yurt dişına gidebilme imkânlarının olması, yarışma olanakları sunulması, iyi enstrüman bulabilmede zorlukları aşılması, üstün yetenekli çocuklar için fonlar açılması, maddi ve manevi destekler ailenin devletten ve özel müteşebbislerden beklentileridir.

Ailenin; çocukla empati kurmanın, onunla ilgilenmenin, araştırmanın ve birlikte öğrenmenin önemine yönelik düşünceleri ise rehber olma özelliğindedir.

Bu bilgiler 1şı ̆̆ında;

Devlet harika çocuk yasasını acilen aktifleştirmelidir.

Yetenekli çocuklar için fonlar açılmalıdır.

Sponsorları bilgilendirme toplantıları yapılmalıdır.

Ülke genelindeki tüm devlet orkestralarında her yıl düzenli olarak konser desteği verilmelidir. 
Yarı zamanlı konservatuvar modelinin ülke genelindeki tüm konservatuvarlarda zorunlu hale gelmesi sağlanmalı ve bu okullara kadro desteği verilmelidir.

Konservatuvar eğitimcileri iki yılda bir ülke genelinde yetenek taraması yapmalıdır.

Yurt dişı ders alma, konser verme, masterclass, atölye çalışmalarına katılma imkanları ve destekleri sağlanmalıdır.

Keman ve araç gereçlerine yönelik burslar verilmelidir.

\section{KAYNAKÇA}

Kaufmann, H. L. (2000). Batı Müziğinden Küçük Öyküler, Çev: M. Halim Spatar, İstanbul: Pencere Yayınları.

Lavignac, A. (1939) Musiki Terbiyesi, Çev: Abdülhalik Derker, İstanbul: Kanaat Kitapevi.

Say, A. (2005). Müzik Öğretimi, Ankara: Müzik Ansiklopedisi Yayınları.

Say, F. (2001). Uçak Notları, (3. baskı) Ankara: Müzik Ansiklopedisi Yayınları.

Türkmen, E. F. (2016). Müzik Ĕ̆itiminde Öğretim Yöntemleri, Ankara: Pegem Akademi Yayıncılık.

Williams, L. (1998). Çocuğunuzu Keşfedin, İstanbul: Hayat Yayıncilik.

Yalman, A. (2017). Beş Bin Yıllık Kültürümüzün Sesi Müzik, İstanbul: Seçil Ofset. 